\title{
OPEN Decline of six native mason bee species following the arrival of an exotic congener
}

\author{
Kathryn A. LeCroy ${ }^{1 凶}$, Grace Savoy-Burke ${ }^{2}$, David E. Carr ${ }^{1}$, Deborah A. Delaney ${ }^{2}$ \& \\ T’ai H. Roulston ${ }^{1}$
}

A potential driver of pollinator declines that has been hypothesized but seldom documented is the introduction of exotic pollinator species. International trade often involves movement of many insect pollinators, especially bees, beyond their natural range. For agricultural purposes or by inadvertent cargo shipment, bee species successfully establishing in new ranges could compete with native bees for food and nesting resources. In the Mid-Atlantic United States, two Asian species of mason bee (Osmia taurus and $O$. cornifrons) have become recently established. Using pan-trap records from the Mid-Atlantic US, we examined catch abundance of two exotic and six native Osmia species over the span of fifteen years (2003-2017) to estimate abundance changes. All native species showed substantial annual declines, resulting in cumulative catch losses ranging 76-91\% since 2003 . Exotic species fared much better, with 0 . cornifrons stable and 0 . taurus increasing by $800 \%$ since 2003. We characterize the areas of niche overlap that may lead to competition between native and exotic species of Osmia, and we discuss how disease spillover and enemy release in this system may result in the patterns we document.

International trade creates opportunities for plant and animal species to be intentionally or inadvertently introduced into novel ecosystems where they may interact with native species. One outcome of species introductions is the potential for competitive interactions with native species, especially those that are most closely related to the introduced species. When closely related species co-occur and overlap in key parts of their life cycle, negative competitive interactions may result, potentially altering ecological and evolutionary trajectories ${ }^{1}$. The success of exotic species establishing in their new range may be facilitated by several factors, including escaping enemies from its home range ${ }^{2}$ and introducing novel enemies, such as exotic diseases, to native competitors in the new range ${ }^{3}$.

Bees (Hymenoptera: Anthophila) are a group of insects with great potential for evaluating the impacts of introduced species on native species, both as perpetrators and casualties, due in part to their anthropogenic associations. Bee species have been intentionally shipped around the world for agricultural pollination and become naturalized in novel environments ${ }^{4-7}$. In addition to intentional introductions, other bee species have been accidentally transported to novel environments via cargo that they nest inside, including wooden packing crates $^{8}$ and lumber for furniture-making ${ }^{9}$. In North America alone, at least thirty-nine exotic bee species have become naturalized, with many spreading extensively since they were first observed ${ }^{10}$ but no solitary species have been extensively monitored for impacts.

Ecological effects of introduced exotic bees on native bees have been hypothesized ${ }^{7,11}$, and studies have recorded range contractions, reduced abundance, or the complete disappearance of native bee species following introductions of social honey bees and bumble bees for agricultural pollination ${ }^{12-14}$. However, of the exotic bee species known to occur in North America, the majority are from the solitary, cavity-nesting family Megachilidae ${ }^{10,15}$. At present, there is little understanding about the impacts of the establishment and spread of introduced solitary bee species on local native bee populations ${ }^{16,17}$. There has been little monitoring of native megachilid communities to determine their population trajectories in the added presence of closely-related exotic competitors.

In North America, the megachilid genus Osmia consists of cavity-nesting bees called "mason bees" with flight periods in the spring and early summer, with great chances of phenological overlap among congeners in activities such as foraging and nesting. Approximately twenty Osmia species are native to the Mid-Atlantic United States (Fig. 1) $)^{18}$. In addition to native Osmia, two mason bee species introduced from Asia have recently naturalized 

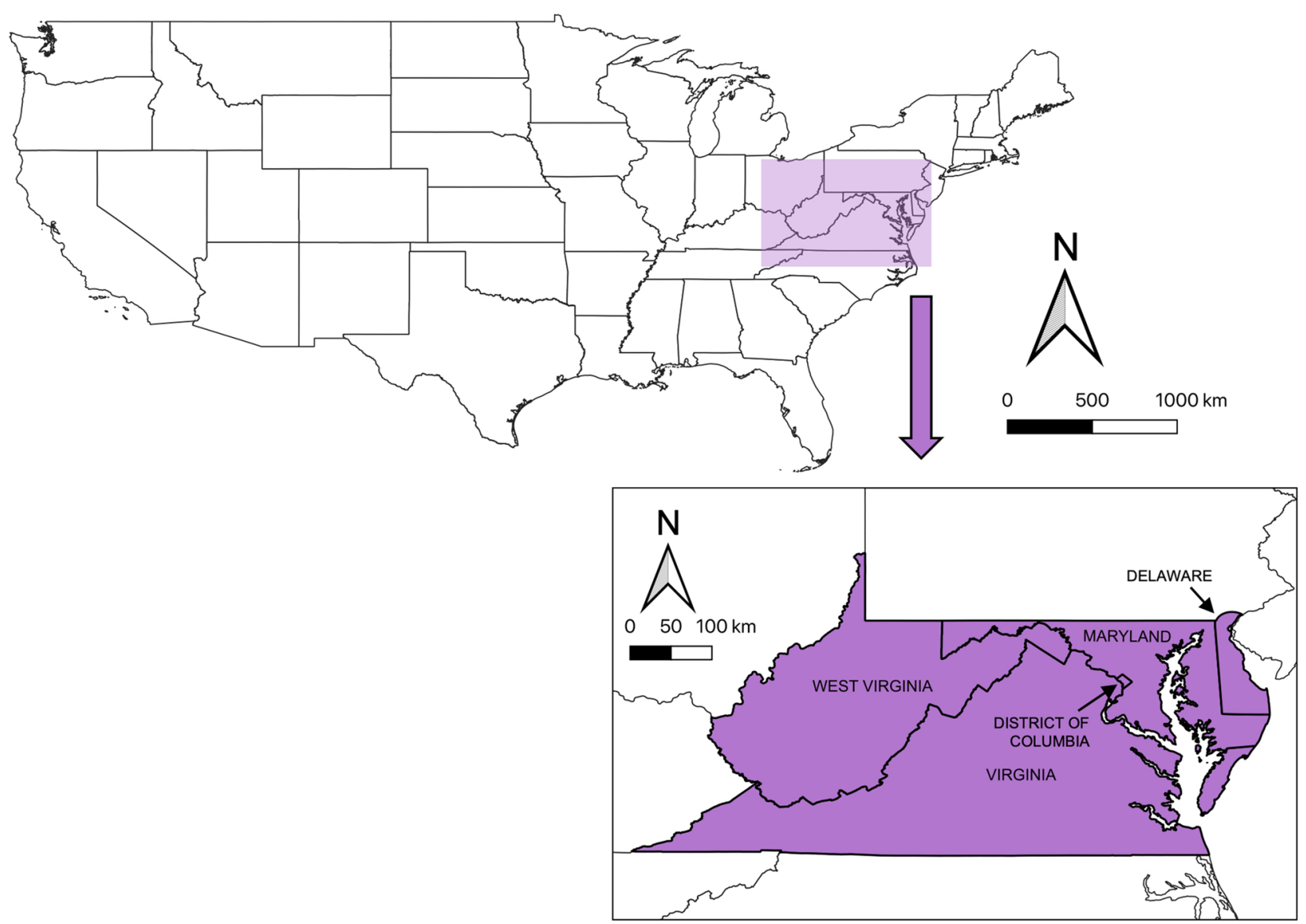

Figure 1. Map of the continental United States of America. Shaded box designates general sampling area of the Mid-Atlantic Region, with inset map depicting states and territory where sampling events were conducted.

in the region. The Japanese horn-faced bee, Osmia cornifrons Radoszkowski, was intentionally introduced from Japan by the United States Department of Agriculture (USDA) in the 1970s for crop pollination services ${ }^{19}$. In 2002, another mason bee from Asia, Osmia taurus Smith, was first documented in the United States, without record of its being intentionally imported ${ }^{20}$.

With multiple introductions of Osmia species to North America, this group is well-suited for examining impacts of exotic species on a community of native congeners. This study sought to evaluate any changes in abundances of native and exotic Osmia species over thirteen years in the Mid-Atlantic region of the United States following the detection of the second introduced mason bee species, Osmia taurus.

\section{Methods}

Study system. Bees in the genus Osmia (Family Megachilidae) are solitary, cavity-nesting species. They are referred to as "mason bees" for their mason-like use of mud, masticated leaf pulp, or other substrates to partition brood cell chambers and seal nest entrances. Osmia in North America are generally univoltine and commonly active mainly in spring to early summer in temperate North America ${ }^{21}$.

Data collection. A combined, long-term ecological monitoring dataset of bees (Hymenoptera: Anthophila) was used to evaluate changes in raw abundance of springtime Osmia (Family Megachilidae) species. This data set was contributed by authors G.S.-B. and D.A.D. ("Delaware dataset"), a network of citizen science program participants coordinated by Sam Droege at the Patuxent Wildlife Refuge (Beltsville, MD USA) ("Patuxent dataset”), and a network of citizen science program participants coordinated by authors K.A.L. and T.H.R. at Blandy Experimental Farm ("Blandy dataset"). The most concentrated sampling efforts occurred in the Mid-Atlantic United States of Delaware, Maryland, Virginia, and West Virginia, as well as the District of Columbia (Fig. 1). These sampling events were conducted by citizen science program participants and research coordinators, and sampling events followed a general pan-trapping protocol ${ }^{22,23}$ in which plastic bowls filled with a preservative trapping medium were placed in open landscapes to catch flying invertebrates.

Trapping medium consisted of either soapy water or a 50:50 water to propylene glycol solution. Bowl sizes within our sampling events were equally sized but ranged from a volume capacity of $3.25 \mathrm{oz}$. up to $16 \mathrm{oz}$. across sampling events, with over $95 \%$ of sampling events using 3.25 oz., 3.5 oz., or 12 oz. bowl sizes. Previous research has found no significant relationship between bowl size and number of bees caught in pan-trapping using 
containers up to $12 \mathrm{oz}^{24,25}$, but greater bee catch abundance has been observed using $20 \mathrm{oz}$. bowls compared to smaller-sized bowls ${ }^{26}$. The number of bowls deployed in a given sampling event ranged from three to 250 , with a median of nine bowls. The duration of sampling events ranged from one to 50 days, with a median of seven days. Collected specimens were cleaned, pinned, entered into a database, identified, and verified by Sam Droege to the lowest taxonomic category possible (species in most cases). This region of the Mid-Atlantic United States is where the exotic Osmia cornifrons was intentionally introduced ${ }^{19}$ and where another exotic species (O. taurus) was first recorded ${ }^{20}$.

Data filtering. Prior to analyses, we extracted from the combined dataset all regional records of Osmia that were identified to species (or to genus if unable to classify to species) and contained complete location information (latitude and longitude coordinates). We limited our dataset to years in which all specimens captured within each sampling event were identified. These years were 2003-2015 inclusively for the Patuxent data set, 2014 and 2015 for the Delaware dataset, and 2017 for the Blandy dataset. Further, we examined all commentary fields in the dataset and excluded all sampling events that noted inclement weather. We did this in order to reduce the likelihood of failed captures being scored as records of absence when they might actually represent poor conditions for sampling. Because the colors of bowls used in pan-trapping surveys can impact their attractiveness to bees and therefore impose a detection bias ${ }^{27}$, sampling events were excluded if they did not deploy all three of the most effective colors known to collectively attract the most bees, including Osmia: fluorescent blue, white, and fluorescent yellow ${ }^{24}$.

We also chose to exclude one sampling event from the Patuxent dataset in 2010 in which 548 individual Osmia were captured in a single day, the largest catch in the combined dataset (the next largest filtered sampling event captured only 85 individuals over 30 days). Of the 548 specimens in that single sample, 539 were identified as Osmia taurus. With concern that this specific sampling event may have been conducted directly by a large nesting aggregation of $O$. taurus, in such a way that other sampling events were not, we chose to exclude this sampling event from our data set (but see Supplementary Table S1 for estimate of O. taurus with inclusion of this outlier). Finally, in order to maximize our ability to detect trends within species over time, only Osmia species with greater than 50 specimen records were selected for species-level analysis (Table 1). Osmia species with greater than 50 specimen records included six native species (Osmia atriventris Cresson; O. bucephala Cresson; O. collinsiae Robertson; O. georgica Cresson; O. lignaria Say; and O. pumila Cresson) and two exotic species (O. cornifrons Radoszkowski, and O. taurus Smith).

Overall, along with removing 548 Osmia specimens from the single sampling event in 2010 described above, we also removed 14 sampling events (consisting of 47 Osmia specimens) due to bad weather, and another 355 sampling events (consisting of 3021 Osmia specimens) were excluded due to not employing all three bowl colors simultaneously. In grand total, 370 sampling events with 3616 Osmia specimens were excluded from all datasets, and a remaining 5901 Osmia specimens from 1125 sampling events were used for analyses.

Spatial variation in sampling effort. Sampling events were not uniformly distributed across space. In order to reduce the potential for geographic bias in sampling intensity to distort perceived temporal patterns, we combined nearby sites through a process of spatial clustering. We used the known average female intertegular (IT) span for each of the eight Osmia species analyzed in this study to calculate an average typical foraging distance using previously published parameters ${ }^{28}$. Across the eight species, the calculated typical foraging distances ranged from $0.22 \mathrm{~km}$ (O. pumila), up to $1.72 \mathrm{~km}$ (O. bucephala). The average typical foraging distance of all eight Osmia species was estimated at $0.63 \mathrm{~km}$. We decided to treat $0.63 \mathrm{~km}$ as a foraging radius, and we used $1.2 \mathrm{~km}$ (roughly twice the foraging radius) as a threshold distance for clustering two sampling sites. Thus, if two sampling events occurred within $1.2 \mathrm{~km}$ of each other, those sampling events were assigned to a common spatial cluster. This was done iteratively until all sampling events were assessed. After all sampling events were subjected to this clustering process, any cluster that contained sampling events spanning a total geographic distance greater than $1.2 \mathrm{~km}$ were then subjected to an algorithm termed affinity propagation, which broke down these larger clusters into a calculated number of smaller clusters based on the relative distances of sites within each cluster ${ }^{29}$.

Sampling events occurring within the same year and assigned to the same spatial cluster had their catch abundance data pooled. In this manner, spatial cluster-year is used as a random effect in the statistical analysis to control for the uneven spatial structure of the dataset to the extent of typical foraging distances. From 1125 sampling events occurring from 2003 to 2017, this process produced a total of 398 spatial cluster-years from 298 spatial clusters.

Temporal variation in sampling effort. Sampling events varied in the number of bowls used and event duration, which in turn can impact bee captures and therefore detection likelihood ${ }^{30}$. In order to account for this variation in sampling effort, the number of days of each sampling event and the number of bowls deployed for each sampling event were multiplied together to produce "bowl days." These bowl days were then summed within each spatial cluster-year, producing an aggregate sampling effort metric. Compared to alternative measures, this metric was found to be the strongest predictor explaining the abundance of Osmia captured in sampling events ( specimen abundance $=-18.88709+7.71731^{\star}$ aggregate sampling effort, $\mathrm{F}(1378)=74.18, p<0.0001, \mathrm{R}^{2}=0.1646$ ) and thus it was included as an offset variable in all statistical analyses examining capture abundance over time. Within-year variation in sampling effort was also evaluated (see Supplementary Information Methods).

Statistical analyses. The change in abundance over time was modeled both for the pooled dataset of all Osmia records and for each Osmia species (with n > 50) independently using Generalized Linear Mixed Models 


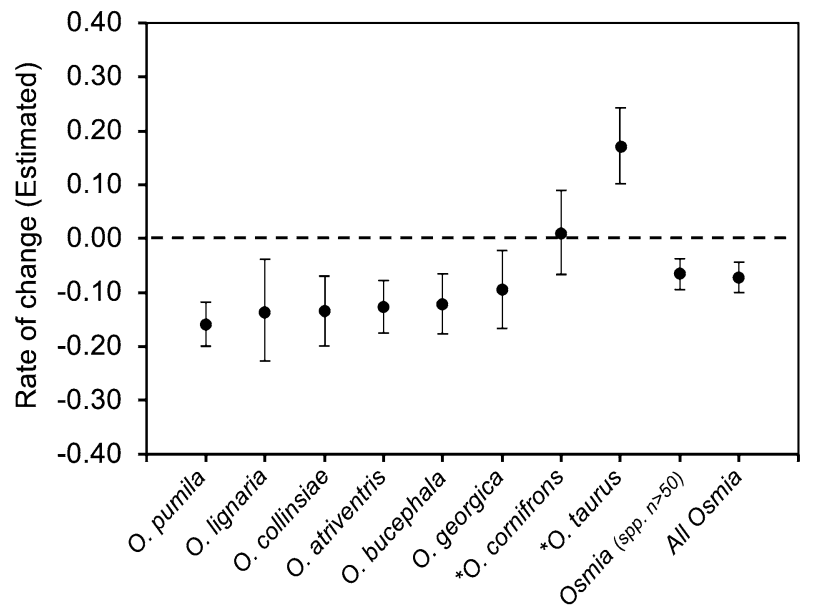

Figure 2. Estimated rates of yearly change for models of each species-specific and genus-wide analysis performed, with 95\% confidence intervals. Estimates in original scale (reverse i-link) are displayed. Species labeled with an asterisk $\left(^{*}\right)$ are exotic to North America.

\begin{tabular}{|l|l|l|l|l|l|l|l|}
\hline Species or Genus & Native/Exotic & $\boldsymbol{n}$ & Model & $\begin{array}{l}\text { Estimated mean change } \\
\text { per year }\end{array}$ & SE & $\boldsymbol{P}$ & $\begin{array}{l}\text { Percent mean change } \\
\text { per year }\end{array}$ \\
\hline Osmia atriventris & Native & 442 & NB & $\mathbf{0 . 8 7 2 3}$ & $\mathbf{0 . 0 2 4 5}$ & $<.0001$ & $-\mathbf{1 2 . 7 7}$ \\
\hline Osmia bucephala & Native & 217 & NB & $\mathbf{0 . 8 7 7 4}$ & $\mathbf{0 . 0 2 7 9}$ & $<.0001$ & $-\mathbf{1 2 . 2 6}$ \\
\hline Osmia collinsiae & Native & 135 & NB & $\mathbf{0 . 8 6 3 4}$ & $\mathbf{0 . 0 3 2 5}$ & $\mathbf{0 . 0 0 0 2}$ & $-\mathbf{1 3 . 6 6}$ \\
\hline Osmia cornifrons & Exotic & 618 & NB & 1.0084 & 0.0393 & 0.8310 & -0.840 \\
\hline Osmia georgica & Native & 293 & NB & $\mathbf{0 . 9 0 3 0}$ & $\mathbf{0 . 0 3 6 3}$ & $\mathbf{0 . 0 1 2 6}$ & $-\mathbf{9 . 7 0}$ \\
\hline Osmia lignaria & Native & 76 & NB & $\mathbf{0 . 8 6 2 2}$ & $\mathbf{0 . 0 4 7 5}$ & $\mathbf{0 . 0 0 8 2}$ & $-\mathbf{1 3 . 7 8}$ \\
\hline Osmia pumila & Native & 1588 & NB & $\mathbf{0 . 8 4 0 3}$ & $\mathbf{0 . 0 2 0 5}$ & $<.0001$ & $-\mathbf{1 5 . 9 7}$ \\
\hline Osmia taurus & Exotic & 2288 & NB & $\mathbf{1 . 1 6 9 9}$ & $\mathbf{0 . 0 3 5 5}$ & $<.0001$ & $+\mathbf{1 6 . 9 9}$ \\
\hline Genus Osmia $(n>50)$ & Both & 5657 & NB & $\mathbf{0 . 9 3 3 6}$ & $\mathbf{0 . 0 1 4 4}$ & $<.0001$ & $-\mathbf{6 . 6 4}$ \\
\hline Genus Osmia (all) & Both & 5901 & NB & $\mathbf{0 . 9 2 7 5}$ & $\mathbf{0 . 0 1 4 2}$ & $<.0001$ & $-\mathbf{7 . 2 5}$ \\
\hline
\end{tabular}

Table 1. Results output from models for each species-specific and genus-wide analysis performed. Estimates are given on original scale. Species-specific models must have had greater than 50 specimens to be considered for analyses. $\mathrm{NB}=$ Negative Binomial distribution selected for analysis (as described in Methods section). Boldface indicates models with significance at $p<0.05$.

in SAS 9.4 with PROC GLIMMIX. Raw abundance for each spatial cluster-year was the dependent variable, and spatial cluster was specified as a random effect, with a random intercept specified for spatial cluster. Year was specified as a fixed effect, and the log-transformed aggregate sampling effort metric ("bowl days") for each spatial cluster-year was used as an offset variable. The appropriate model response distribution was selected for each species (assessed by evaluating residuals and fit statistics from models using the Poisson, generalized Poisson ${ }^{31}$, and negative binomial distributions), all of which followed a negative binomial distribution (Table 1). All models were specified with a log link function.

Analyses at the level of genus Osmia were performed two ways, one including only records from species that had greater than 50 specimens, and the second including all specimen records regardless of the quantity per species or whether they were identified to the species level. For each species and genus-wide model, we inspected the standardized residuals of each model for any remaining spatial autocorrelation using bubble plots, correlograms, variograms, and calculation of Moran's I. We additionally ran these analyses at larger scales beyond $1.2 \mathrm{~km}$ : we conducted analyses following clustering at $3 \mathrm{~km}, 5 \mathrm{~km}, 10 \mathrm{~km}$, and $20 \mathrm{~km}$. Lastly, as a more conservative analysis, we performed analyses at $1.2 \mathrm{~km}$ using only clusters that included at least two years of sampling.

\section{Results}

Overall, 5901 specimen records from 1125 sampling events were analyzed. Annual capture rates for the genus Osmia as a whole significantly decreased at a mean of $6.64 \%$ per year for the species with $\mathrm{n}>50$ specimens, and declining at a mean of 7.25\% per year when all Osmia records were included in the dataset (Fig. 2, Table 1). All six native Osmia were found to be significantly declining in mean raw abundance, ranging from a $9.70 \%$ yearly mean decline (O. georgica) to a $15.97 \%$ yearly mean decline $(O$. pumila). The exotic O. taurus was found to be significantly increasing at a magnitude of $16.99 \%$ per year (Fig. 2, Table 1). The estimated rate of change for 


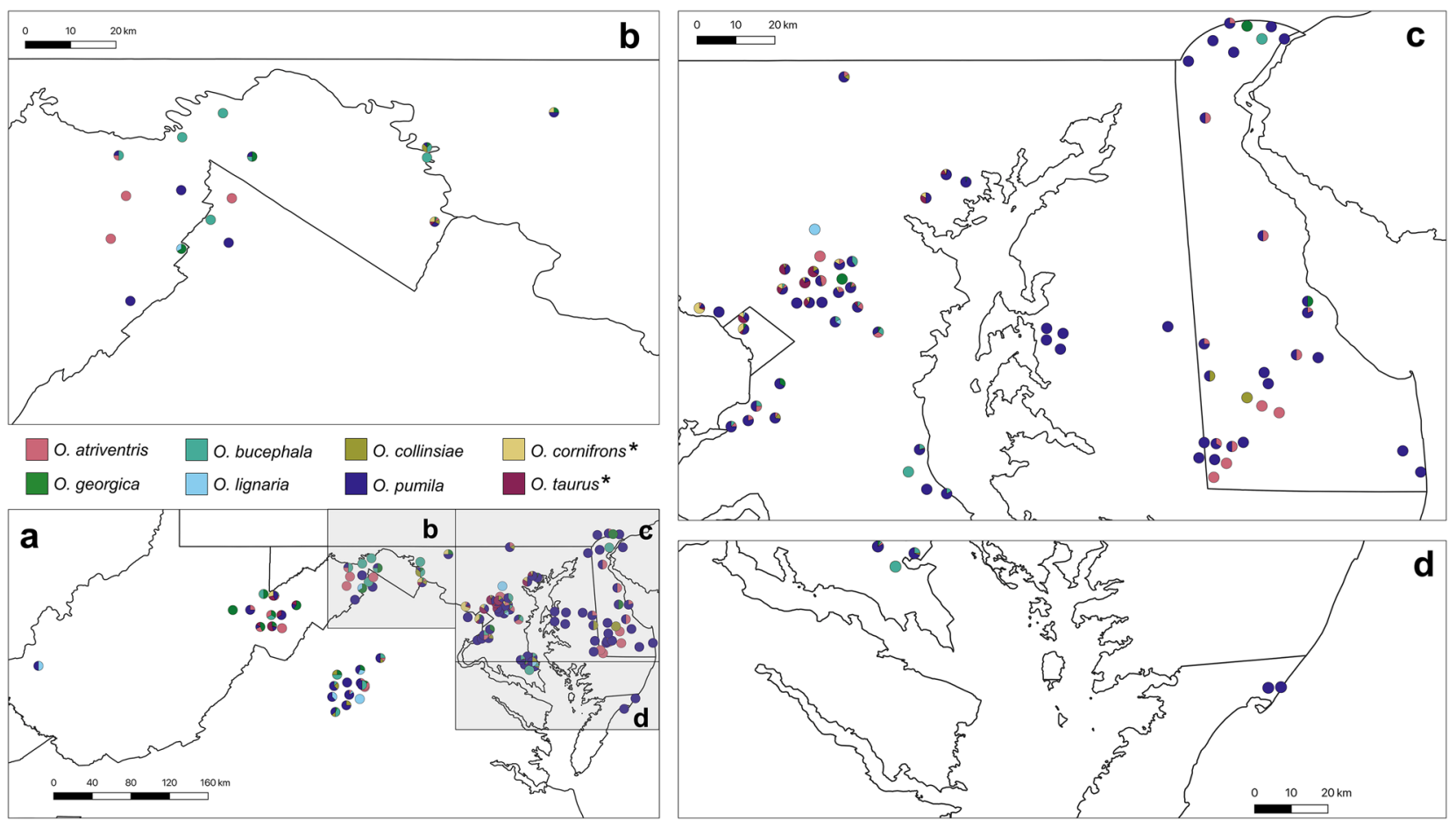

Figure 3. Mason bee (genus Osmia) composition of sites in the Mid-Atlantic Region of the United States, 20032009. Pie charts at each site represent the proportions of Osmia species according to color legend. Placement of pie charts represent approximate location of sampling site. Bee species names accompanied with an asterisk $\left(^{*}\right)$ are exotic to the Mid-Atlantic United States.

exotic and commercially managed O. cornifrons was not significantly different from zero (Fig. 1, Table 1). There was no change in within-year sampling effort across years (Supplementary Table S2, Supplementary Fig. S1).

Residual spatial autocorrelation was found only for O. pumila, such that sites at close distances were more similar (Supplementary Table S4). Geographic breakdowns of Osmia species occurrence are provided in Fig. 3 for 2003-2009 and Fig. 4 for 2010-2017. Using greater clustering thresholds of $3 \mathrm{~km}, 5 \mathrm{~km}, 10 \mathrm{~km}$, and $20 \mathrm{~km}$, we found that all native Osmia species remained in significant decline, O. taurus remained significantly increasing, and O. cornifrons did not change significantly over time (Supplementary Fig. S2). From analysis of only clusters with multiple sampling years, $O$. taurus remained significantly increasing as in the full analysis, O. cornifrons remained insignificant in its estimated change, and all six analyzed native species still were estimated to be experiencing yearly declines (Supplementary Fig. S3, Supplementary Table S5), all of which remained significant with the exception of $O$. lignaria for which statistical power was reduced (only 41 specimens for $O$. lignaria in multi-sampled clusters). However, the estimate of decline (0.9006) remained similar to estimated decline of $O$. lignaria in the main analysis (0.8622) (Supplementary Table S5, Table 1). The landcover types of sampling locations in the early years of the study did not differ from the landcover composition sampled later in the study (Supplementary Table S6).

\section{Discussion}

Dialogue concerning insect declines in the Anthropocene often fails to tease apart the insect "winners" and "losers" 32 . We report a significant surge in the abundance of the exotic solitary bee species Osmia taurus with concurrent losses of all six native Osmia species in our analysis. As a percentage of all Osmia captured, exotic $O$. taurus increased from approximately $22 \%$ of captures in 2003-2009 to being the most commonly caught Osmia species with over $43 \%$ of all captures in 2010-2017. Thus, despite exotic O. taurus being first recorded in the U.S. only in $2002^{20}$, it has now become the most commonly caught Osmia species in the region by far. Given that $O$. cornifrons was intentionally introduced, actively propagated, and shipped around the region at least two decades before $O$. taurus arrived, it is surprising that $O$. taurus has gone from a first record in 2002 to being more commonly collected than $O$. cornifrons in every year since 2009. It does not appear to be a case of mistaken identity, as we have examined regional museum specimens to ascertain that $O$. taurus, which is superficially similar to $O$. cornifrons, wasn't mistakenly identified by researchers as $O$. cornifrons prior to knowledge of the arrival of $O$. taurus in the region (K.A.L. and S. Droege, pers. comm.). A similar rapid rise in abundance of an introduced bee species with concomitant declines in related native species has been reported for native bumble bees in Japan, Argentina, and Chile following the introduction of non-native bumble bees for commercial pollination ${ }^{12-14}$. Our work adds to this understudied field and further highlights the need to monitor native populations when related exotic solitary bee species enter new ecosystems. 


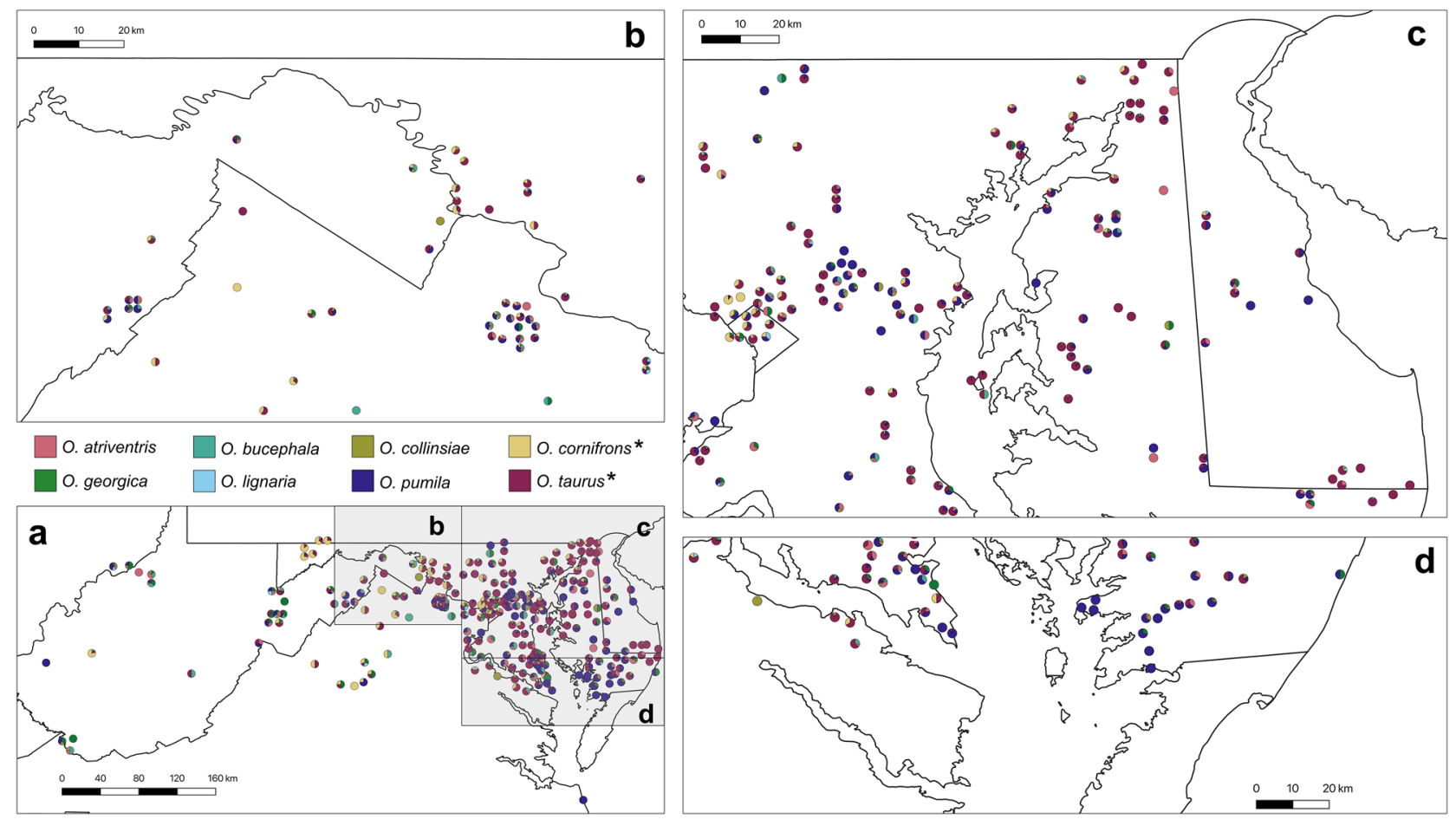

Figure 4. Mason bee (genus Osmia) composition of sites in the Mid-Atlantic Region of the United States, 20102017. Pie charts at each site represent the proportions of Osmia species according to color legend. Placement of pie charts represent approximate location of sampling site. Bee species names accompanied with an asterisk $\left(^{*}\right)$ are exotic to the Mid-Atlantic United States.

The reasons for the success of Osmia taurus relative to that of native Osmia are not known, but there are several plausible mechanisms: competition for resources, habitat changes favoring the introduced species, release from natural enemies in the introduced range, and concurrent introduction of novel diseases with the exotic species. If competition were the primary driver of declines between O. taurus and native species, then we would expect a gradient of change among native species based on their amount of niche overlap with $O$. taurus. In this case, O. lignaria would likely be the native species in greatest decline. It is the only native species in the same subgenus as both exotic species (subgenus Osmia), and it uses similarly-sized cavities as the exotic species ${ }^{21,33}$. Osmia lignaria is one of only two native species to emerge as early as O. cornifrons and O. taurus (Supplementary Methods, Supplementary Table S3), and it is the only native species in this study to also use mud as its primary brood cell partition material (the other native Osmia in this study use masticated leaves) $)^{21,33,34}$. In the United States, O. lignaria uses similar floral resources to the exotic O. cornifrons ${ }^{19,35}$, and although floral preferences of O. taurus have yet to be studied in North America, it is known to collect floral resources from the same groups of plants as O. cornifrons in Japan ${ }^{33}$. Thus, O. lignaria would seem to have the greatest potential among the native species to be impacted by the introduction of these exotic species to their native habitat. Although the mean annual decline of $O$. lignaria is among the greatest in magnitude of the native species analyzed, its confidence intervals overlap with all other native species (Fig. 2, Table 1), indicating that ecological factors beyond competition are likely playing a role in native species declines.

Another possible mechanism is that of disease spread from exotic mason bee species to native mason bees. Introduction of exotic species along with their diseases can dramatically reduce the population of native species that are closely related or functionally similar ${ }^{3,36,37}$. One of the main diseases affecting the bee genus Osmia worldwide is chalkbrood ${ }^{38}$, caused by a group of fungi in the genus Ascosphaera. Several species of Ascosphaera are native to North America, but a recent study in Ithaca, New York (U.S.A.) found that the exotic O. cornifrons was harboring a Japanese species of Ascosphaera (A. naganensis), which it had apparently brought from its native range to the introduced range ${ }^{39}$. The pathogenicity of this Ascosphaera species is still unclear, as some Ascosphaera are saprophytic rather than parasitic and many other Ascosphaera species have not been studied ${ }^{40}$. It is also unknown to what extent this fungal species has moved from its exotic host into native hosts, but it remains an important avenue of study. In addition to Ascosphaera naganensis, the parasitoid wasp Monodontomerus osmiae Kamijo, known to attack O. taurus and O. cornifrons in Japan ${ }^{41,42}$, was recorded in North America in 2002 in Silver Spring, Maryland ${ }^{43}$. Its abundance and impact on native Osmia in the region, and how it came to be introduced into North America, however, have yet to be discerned. Similarly, the palearctic spider beetle Ptinus sexpunctatus Panzer, was first detected in North America in 2003 in the nests of Osmia lignaria ${ }^{44}$. It is known to be very destructive to Osmia nests in Europe and may represent a new, broad threat to North American Osmia.

Reduced pressure from natural enemies may be another likely pathway of successful invasion by exotic species $^{2,45}$ and has been documented for cavity nesting bees in North America ${ }^{46}$. No parasite studies have been 
carried out for Osmia taurus in North America, so it is currently unknown if this mechanism contributes to its successful proliferation. In its native range in Japan, O. taurus and O. cornifrons are associated with natural enemies across eight orders of arthropods ${ }^{33,47}$. In North America, five nest associates of $O$. cornifrons have been reported, four of which are congeners to typical nest associates of O. cornifrons in Japan: Chaetodactylus (parasitic mites), Monodontomerus (parasitoid wasps), Ptinus (spider beetles), and Tribolium (flour beetles). The fifth associate is in the genus Tricrania (Meloidae), which is endemic to North America, but a meloid species in the genus Meloe is reported to attack $O$. cornifrons in $\operatorname{Japan}^{33}$. Thus, similar kinds of natural enemies were already present when Osmia taurus arrived, although we don't know the extent to which the native enemies are attacking $O$. taurus. One reason $O$. cornifrons may have been selected for import into the United States instead of Osmia taurus was because $O$. taurus experienced high levels of natural enemy attack in Japan ${ }^{33,48,49}$. If $O$. taurus is able to escape the frequency of enemy attack it experiences in its native range, it may exhibit higher reproductive output in an introduced environment with fewer natural enemies. Future studies should examine whether $O$. taurus is suffering less from natural enemies in its introduced range compared with native Osmia and thereby gaining an advantage over potential competitors.

Abiotic factors such as climate change may favor the proliferation of some species over others, but in the current study there is no evidence for habitat changes which favor the introduced species while disfavoring native species. However, the faster spread of Osmia taurus than Osmia cornifrons may reflect broader climatic tolerance in the introduced range. In Japan, where both species are native, O. cornifrons is restricted to the central and northern parts of the country, whereas O. taurus occurs throughout. Professor Yasuo Maeta ${ }^{33}$ hypothesized that the restricted distribution of $O$. cornifrons in Japan may reflect developmental failure in the southern and coastal climates: either, the hot summer prevented successful prepupal development, or the warm fall failed to induce overwintering diapause in time. Osmia cornifrons was selected for introduction into the United States due in part to a climatic match between its native range and that of temperate North America ${ }^{19}$. If $O$. taurus is able to tolerate a wider variety of climate conditions than O. cornifrons, then it may be poised to spread much further in its exotic range, particularly in warmer areas, than O. cornifrons. Range expansions or shrinkages in native Osmia species due to a warming climate in the Mid-Atlantic United States have yet to be evaluated but remain crucial for fully understanding cause(s) of native Osmia declines.

Another finding of note in our study was that the exotic O. cornifrons did not exhibit any significant changes in raw abundance over the thirteen-year period, and it is unclear if the lack of a significant trend indicates stability over time or lack of precision in estimates due to spatial and temporal variability. One factor that may contribute to its variability is its continual management and release into the environment as an agricultural pollinator of fruit trees in the Mid-Atlantic United States ${ }^{50,51}$. Although we are not aware of the release of commercially-managed $O$. cornifrons directly at any sites in our dataset, the regional production, protection, and redistribution of $O$. cornifrons could result in locally supplemented populations, providing a competitive advantage against native species and a buffer against the fast-spreading $O$. taurus.

This study takes advantage of an existing bee monitoring program that provides substantial documentation of bee populations over a large geographic area with nearly two decades of sampling made possible by citizen science program paticipants. Although Osmia are captured at lower rates than many other groups of bees using pan-trapping ${ }^{52}$ and thus may produce estimates with less precision than for more abundantly captured groups, this combined dataset provides the most information about Osmia abundances at this scale in North America to date. An affordable, general collecting protocol replicated over time and space with the help of many individuals such as citizen science program participants can provide a wealth of data, including information on changes in species abundance over time and exotic species detection and spread. Such monitoring is needed in order to recognize species declines in time to study their causes as well as prevent their loss from the landscape.

\section{Code availability}

The code used to produce the results and figures in this paper is available from the corresponding author upon request. The mixed models in this study were run using Statistical Analytics Suite (SAS) 9.4, a commercial software product.

\section{Data availability}

All datasets for the main and supplementary analyses are available as Supplementary Information.

Received: 24 April 2020; Accepted: 13 October 2020

Published online: 30 October 2020

\section{References}

1. Brown, W. L. \& Wilson, E. O. Character displacement. Syst. Zool. 5, 49 (1956).

2. Jeffries, M. \& Lawton, J. Enemy free space and the structure of ecological communities. Biol. J. Linn. Soc. 23, 269-286 (1984).

3. Reynolds, J. D. Crayfish extinctions and crayfish plague in central Ireland. Biol. Conserv. 45, 279-285 (1988).

4. Stephen, W. P. Solitary bees in North American agriculture: A perspective. In For non-native crops, whence pollinators of the future (eds Strickler, K. \& Cane, J. H.) 41-66 (Entomological Society of America, 2003).

5. Goulson, D. \& Hanley, M. E. Distribution and forage use of exotic bumblebees in South Island New Zealand. N. Z. J. Ecol. 28, 225-232 (2004).

6. Morales, C. L. \& Aizen, M. A. Invasive mutualisms and the structure of plant-pollinator interactions in the temperate forests of north-west Patagonia. Argentina. J. Ecol. 94, 171-180 (2006).

7. Vergara, C. H. Environmental impact of exotic bees introduced for crop pollination. In Bee Pollination in Agricultural Ecosystems (eds James, R. R. \& Pitts-Singer, T. L.) 145-165 (Oxford University Press, Oxford, 2008).

8. Roberts, R. B. The nesting biology, behavior and immature stages of Lithurge chrysurus, an adventitious wood-boring bee in New Jersey (Hymenoptera: Megachilidae). J. Kans. Entomol. Soc. 51, 735-745 (1978). 
9. Mangum, W. A. \& Brooks, R. W. First records of Megachile (Callomegachile) sculpturalis Smith (Hymenoptera: Megachilidae) in the Continental United States. J. Kans. Entomol. Soc. 70, 140-142 (1997).

10. Russo, L. Positive and negative impacts of non-native bee species around the world. Insects 7, 69 (2016).

11. Goulson, D. Effects of introduced bees on native ecosystems. Annu. Rev. Ecol. Evol. Syst. 34, 1-26 (2003).

12. Inoue, M. N., Yokoyama, J. \& Washitani, I. Displacement of Japanese native bumblebees by the recently introduced Bombus terrestris (L.) (Hymenoptera: Apidae). J. Insect Conserv. 12, 135-146 (2008).

13. Morales, C. L., Arbetman, M. P., Cameron, S. A. \& Aizen, M. A. Rapid ecological replacement of a native bumble bee by invasive species. Front. Ecol. Environ. 11, 529-534 (2013).

14. Schmid-Hempel, R. et al. The invasion of southern South America by imported bumblebees and associated parasites. J. Anim. Ecol. 83, 823-837 (2014).

15. Cane, J. H. Exotic non-social bees (Hymenoptera: Apoidea) in North America: Ecological implications. In For non-native crops, whence pollinators of the future (eds Strickler, K. \& Cane, J. H.) 113-126 (Entomological Society of America, 2003).

16. Paini, D. R. Impact of the introduced honey bee (Apis mellifera) (Hymenoptera: Apidae) on native bees: A review. Austral Ecol. 29, 399-407 (2004).

17. Mallinger, R. E., Gaines-Day, H. R. \& Gratton, C. Do managed bees have negative effects on wild bees? A systematic review of the literature. PLoS ONE 12, e0189268 (2017).

18. Ascher, J. S. \& Pickering, J. Apoidea species-identification guide-Discover Life. https://www.discoverlife.org/mp/20q?guide =Apoidea_species\&flags=HAS: $(2020)$.

19. Batra, S. Osmia cornifrons and Pithitis smaragdula, two Asian bees introduced into the United States for crop pollination. in Proceedings 4th International Symposium on Pollination. Maryland Agricultural Experimental Station Miscellaneous Publication (1978).

20. Droege, S. USGS PWRC - Native Bee Inventory and Monitoring Lab (BIML). https://doi.org/10.15468/6AUTVB (2020).

21. Cane, J. H., Griswold, T. \& Parker, F. D. Substrates and materials used for nesting by North American Osmia bees (Hymenoptera: Apiformes: Megachilidae). Ann. Entomol. Soc. Am. 100, 350-358 (2007).

22. Droege, S., Engler, J., Sellers, E. \& O’Brien, L. National Protocol Framework for the Inventory and Monitoring of Bees (U.S. Fish and Wildlife Service, Washington, D.C., 2016).

23. LeBuhn, G., Droege, S., Connor, E., Gemmill-Herren, B. \& Azzu, N. Protocol to Detect and Monitor Pollinator Communities: Guidance for Practitioners (Food and Agriculture Organization of the United Nations, Rome, 2016).

24. Droege, S. Impact of color and size of bowl trap on numbers of bees captured. J. Insect Conserv. https://doi.org/10.1007/s1084 1-016-9914-6 (2006).

25. Gonzalez, V. H. et al. Effect of pan trap size on the diversity of sampled bees and abundance of bycatch. J. Insect Conserv. https:// doi.org/10.1007/s10841-020-00224-4 (2020).

26. Wilson, J. S. et al. Sampling bee communities using pan traps: Alternative methods increase sample size. J. Insect Conserv. 20, 919-922 (2016).

27. Westphal, C. et al. Measuring bee diversity in different European habitats and biogeographical regions. Ecol. Monogr. 78, 653-671 (2008).

28. Greenleaf, S. S., Williams, N. M., Winfree, R. \& Kremen, C. Bee foraging ranges and their relationship to body size. Oecologia 153, 589-596 (2007).

29. Frey, B. J. \& Dueck, D. Clustering by passing messages between data points. Science 315, 972-976 (2007).

30. Shapiro, L. H., Tepedino, V. J. \& Minckley, R. L. Bowling for bees: optimal sample number for "bee bowl" sampling transects. J. Insect Conserv. 18, 1105-1113 (2014).

31. Joe, H. \& Zhu, R. Generalized poisson distribution: The property of mixture of poisson and comparison with negative binomial distribution. Biom. J. 47, 219-229 (2005).

32. Didham, R. K. et al. Interpreting insect declines: Seven challenges and a way forward. Insect Conserv. Divers. 13, 103-114 (2020).

33. Maeta, Y. Comparative studies on the biology of bees of the genus Osmia of Japan, with special reference to their management for pollinations of crops (Hymenoptera: Megachilidae). Bull. Tohoku Nat. Agric. Exp. Stn. 57, 1-221 (1978).

34. Bosch, J. \& Kemp, W. P. How to Manage the Blue Orchard Bee: As an Orchard Pollinator (Sustainable Agriculture Network, San José, 2001).

35. Kraemer, M. E., Favi, F. D. \& Niedziela, C. E. Nesting and pollen preference of Osmia lignaria lignaria (Hymenoptera: Megachilidae) in Virginia and North Carolina orchards. Environ. Entomol. 43, 932-941 (2014).

36. Tompkins, D. M., White, A. R. \& Boots, M. Ecological replacement of native red squirrels by invasive greys driven by disease. Ecol. Lett. 6, 189-196 (2003).

37. Prenter, J., MacNeil, C., Dick, J. T. A. \& Dunn, A. M. Roles of parasites in animal invasions. Trends Ecol. Evol. 19, 385-390 (2004).

38. Stephen, W. P., Vandenberg, J. D. \& Fichter, B. L. Etiology and epizootiology of chalkbrood in the alfalfa leafcutting bee, Megachile rotundata, with notes on Ascosphaera species. Oregon State Univ. Agric. Exp. Stn. Bull. 653, 1-10 (1981).

39. Hedtke, S. M., Blitzer, E. J., Montgomery, G. A. \& Danforth, B. N. Introduction of non-native pollinators can lead to transcontinental movement of bee-associated fungi. PLoS ONE 10, e0130560 (2015).

40. Klinger, E. G. Virulence Evolution of Fungal Pathogens in Social and Solitary Bees with an Emphasis on Multiple Infections. (Utah State University, Logan 2015).

41. Kamijo, K. A revision of the species of the Monodontomerinae occurring in Japan (Hymenoptera: Chlacidoidea) [Taxonomic Studies on the Torymidae of Japan, 2]. Insecta Matsumurana 26, 89-98 (1963).

42. Kamijo, K. Description of five new species of Eulophinae from Japan and other notes (Hymenoptera: Chalcidoidea). Insecta Matsumurana 28, 69-78 (1965).

43. Grissell, E. Discovery of Monodontomerus osmiae Kamijo (Hymenoptera: Torymidae) in the New World. Proc. Entomol. Soc. Wash. 105, 243-245 (2003).

44. Majka, C. G., Philips, T. K. \& Sheffield, C. Ptinus sexpunctatus Panzer (Coleoptera: Anobiidae, Ptininae) newly recorded in North America. Entomol. News 118, 73-76 (2007).

45. Torchin, M. E. \& Mitchell, C. E. Parasites, pathogens, and invasions by plants and animals. Front. Ecol. Environ. 2, 183-190 (2004).

46. MacIvor, J. S. \& Packer, L. 'Bee hotels' as tools for native pollinator conservation: A premature verdict? PLoS ONE 10, e0122126 (2015).

47. Park, Y. L. et al. Nest-to-nest dispersal of Chaetodactylus krombeini (Acari, Chaetodactylidae) associated with Osmia cornifrons (Hym., Megachilidae). J. Appl. Entomol. 133, 174-180 (2009).

48. Maeta, Y. \& Kitamura, T. Studies on the apple pollination by Osmia. II. Characteristics and underlying problems in utilizing Osmia. Kontyu 33, 17-34 (1965).

49. Kobayashi, M. Problems in the utilisation of Eristalis cerealis as pollinator. Shokubutsu Boeki 26, 473-478 (1972).

50. Biddinger, D. J. et al. Development of the mason bee, Osmia cornifrons, as an alternative pollinator to honey bees and as a targeted delivery system for biocontrol agents in the management of fire blight. Penn Fruit News 90, 35-44 (2009).

51. West, T. P. \& McCutcheon, T. W. Evaluating Osmia cornifrons as pollinators of highbush blueberry. Int. J. Fruit Sci. 9, 115-125 (2009).

52. Portman, Z. M., Bruninga-Socolar, B. \& Cariveau, D. P. The state of bee monitoring in the United States: a call to refocus away from bowl traps and towards more effective methods. Ann. Entomol. Soc. Am. https://doi.org/10.1093/aesa/saaa010 (2020). 


\section{Acknowledgements}

We thank S. Droege and all citizen science program participants who made data collection possible. We thank R. Spahn for computational assistance. We thank K. Haynes, C. Rodenberg, K. Schoenemann, and E. Spindler for helpful feedback on the manuscript.

\section{Author contributions}

K.A.L., T.H.R., G.S.B., and D.A.D. contributed to data acquisition. K.A.L., G.S.B., D.E.C, and T.H.R. contributed to study design and writing of the manuscript. K.A.L. performed the main analyses and led the writing of the manuscript. K.A.L., G.S.B., and T.H.R. conducted supplementary analyses. All authors read and approved the final manuscript.

\section{Competing interests}

The authors declare no competing interests.

\section{Additional information}

Supplementary information is available for this paper at https://doi.org/10.1038/s41598-020-75566-9.

Correspondence and requests for materials should be addressed to K.A.L.

Reprints and permissions information is available at www.nature.com/reprints.

Publisher's note Springer Nature remains neutral with regard to jurisdictional claims in published maps and institutional affiliations.

Open Access This article is licensed under a Creative Commons Attribution 4.0 International License, which permits use, sharing, adaptation, distribution and reproduction in any medium or format, as long as you give appropriate credit to the original author(s) and the source, provide a link to the Creative Commons licence, and indicate if changes were made. The images or other third party material in this article are included in the article's Creative Commons licence, unless indicated otherwise in a credit line to the material. If material is not included in the article's Creative Commons licence and your intended use is not permitted by statutory regulation or exceeds the permitted use, you will need to obtain permission directly from the copyright holder. To view a copy of this licence, visit http://creativecommons.org/licenses/by/4.0/.

(C) The Author(s) 2020 